\title{
Detection of cytochrome P450 1A1 in North Sea dab liver and kidney
}

\author{
Anders Goksøyr ${ }^{1}$, Håvard E. Larsen ${ }^{1}$, Sonja Blom ${ }^{2}$, Lars Förlin ${ }^{2}$ \\ ${ }^{1}$ Laboratory of Marine Molecular Biology, University of Bergen, HIB, N-5020 Bergen, Norway \\ ${ }^{2}$ Department of Zoophysiology, University of Göteborg, Medicinaregatan 18, S-413 90 Göteborg, Sweden
}

\begin{abstract}
Liver and kidney tissue of dab Limanda limanda were analyzed during the Bremerhaven Workshop by immunochemical and catalytic assays for cytochrome P450 1A1 induction. Antibodies to cod P450 $1 \mathrm{~A} 1$ cross-reacted with a protein of $M_{\mathrm{I}}=58000$ daltons in the dab liver samples, suggested to be the dab P450 1A1 protein. By employing a recently developed indirect ELISA with these antibodies, we observed elevated levels of P450 1A1 protein in the innermost stations of the German Bight transect in both liver and kidney (head and trunk kidney) samples. Ethoxyresorufin O-deethylase (EROD) activities in trunk kidney were also elevated in the innermost stations. Along the drilling station gradient no induction could be detected. Immuno-detection of the cytochrome P450 $1 \mathrm{~A} 1$ induction response should provide a convenient indicator for biological effects of several classes of organic contaminants.
\end{abstract}

\section{INTRODUCTION}

Among various biological indicators studied to detect effects of marine pollutants on organisms, the cytochrome P450 (CYP or P450) monooxygenase induction response is considered to be of great promise (see e.g. Payne et al. 1987, Goksøyr \& Förlin 1992). The response of this system in fish to aromatic and chlorinated hydrocarbons has been studied in a number of laboratory and field studies, traditionally by catalytic assays such as 7-ethoxyresorufin O-deethylase (EROD) or aryl hydrocarbon hydroxylase $(\mathrm{AHH})$. In fish, these activities are believed to represent the catalytic activity of a single CYP form, CYP $1 \mathrm{~A} 1$ or P450 1A1, a member of the CYP 1A subfamily, being responsive to organic contaminants by gene activation. The induction response can also be studied at other levels, such as with nucleotide probes for measuring mRNA levels (Renton \& Addison 1992), or with antibody probes for measuring the translated protein product (reviewed in Goksøyr \& Förlin 1992).

Catalytic measurements have certain disadvantages compared to immunodetection of protein levels, including their critical dependence on fresh samples and time and cost effectiveness. Sampling for catalytic determinations demands fresh processing and/or cryopreservation, conditions that may not be easily met in remote areas, far off-shore, or in developing regions of the world. Simple immunoassays can overcome these problems. By measuring the presence of immunoreacting protein with appropriate antibodies, biological integrity and freshness is not critical in this system, and the assay can be automated so that large numbers of samples can be processed and analyzed simultaneously. Such systems are also more easily adapted to low-cost laboratories.

Using polyclonal antibodies against cod Gadus morhua P450 1A1 (= cod P-450c; Goksøyr 1985), we have developed a simple, indirect enzyme-linked immunosorbent assay (ELISA) for detecting the P450 induction response in fish samples (Goksøyr 1991). The method has been applied to a large number of samples from both laboratory and field studies, generally showing good correlation with contaminant exposure in different species of fish (Goksøyr et al. 1991a, 1991b, Boon et al. 1992).

Although the induction response is generally studied in liver tissue, other organs are also affected by inducing agents. In some cases, studies of induction in extrahepatic tissue may give additional information to that from liver samples (Payne et al. 1984, Pesonen et al. 1987). The fish kidney is divided into the pronephros (head kidney) and mesonephros (trunk kidney). These organs are important in steroidogenesis, 
haematopoiesis and excretion, respectively, functions that may be affected by changes in $\mathrm{P} 450$ levels and activity through endocrine signals. Here, we describe the application of immunodetection of P450 1A1 in the analysis of liver and kidney tissue, and catalytic measurements in kidney, of dab Limanda limanda sampled at different locations in the southern part of the North Sea during the workshop

\section{MATERIALS AND METHODS}

The southern North Sea is a shallow area influenced by inputs from the large continental European rivers. The sampling area in the German Bight is specifically influenced by the Elbe and Weser plumes. The abandoned drilling station gradient was chosen to avoid direct influences from the rivers, but had a single dominating contaminant source foil and drilling mud in the sediment). A detailed description of the sampling areas in the German Bight and around the abandoned oil drilling platform in Dutch waters is given elsewhere (Daan et al. 1992, Stebbing \& Dethlefsen 1992). The dab is the most abundant flatfish in the North Sea, and it has therefore become an important indicator species in pollution monitoring programmes in this area. Data on dab biology relevant for this study are presented by Rijnsdorp et al. (1992). Samples were generally obtained after dissection of the fish on board ship, frozen in liquid nitrogen, and transferred to the laboratory on shore (Alfred-Wegener-Institut, Bremerhaven) for processing of samples. Liver post-mitochondrial supernatants were obtained after $12000 \times g$ centrifugation of the homogenized tissue (Eggens et al. 1992) and microsomes were prepared from a $100000 \times \mathrm{g}$ pellet, as described elsewhere (Renton \& Addison 1992). Head kidney microsomes and trunk kidney post-mitochondrial supernatants were prepared as described previously (Pesonen \& Anderson 1987). Protein was analyzed by the method of Bradford (1976).

Western blotting was performed as described recently (Goksøyr et al. 1991c), using polyclonal rabbit anti-cod P450 1 A1 IgG.

Indirect P450 1A1-ELISA was performed on all these samples by the method of Goksøyr (1991). This method gives results as absorbance units (which are based on the same amount of protein from each sample), a semiquantitative reflection of P450 1A1 protein levels. Liver samples were developed for $10 \mathrm{~min}$, and kidney and gill samples for $30 \mathrm{~min}$ before stopping the colour reaction. Each sample was run in triplicate, and absorbance in 96-well plates (Nunc) was read by a Titertek Multiskan MkII plate reader from Flow Laboratories.

Statistical analyses and presentations were per- formed using the JMP Software for Statistical Visualization (SAS Institute Inc.) on a Macintosh computer.

\section{RESULTS AND DISCUSSION}

Samples were obtained from a large number of dab from most of the stations in the German Bight gradient and the 3 drilling site stations. Analyses were therefore performed separately on sets of liver microsomes from male and female fish, and on a set of liver postmitochondrial supernatants including juvenile and mature fish of both sexes. Both head kidney microsomes and trunk kidney post-mitochondrial supernatants were obtained from male fish.

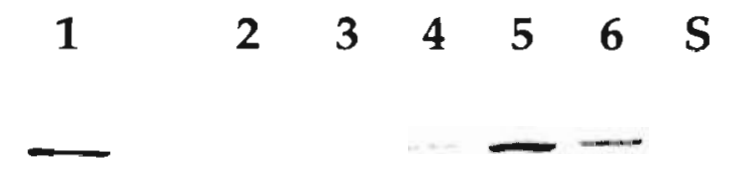

Fig. 1. Limanda limanda. Western blot of liver samples of male dab from the German Bight probed with anti-cod P450 $1 \mathrm{~A} 1 \mathrm{IgG}$. The samples (with stations of capture indicated) are (1) purified cod P450 1A1 ( $\mathrm{M}_{\mathrm{T}}=58000$ daltons), (2) dab 94 (Stn 9), (3) dab 823 (Stn 8), (4) dab 614 (Stn 6), (5) dab 525 (Stn 5), (6) dab 314 (Stn 3), (S) pre-stained molecular weight standards (Bio-Rad)

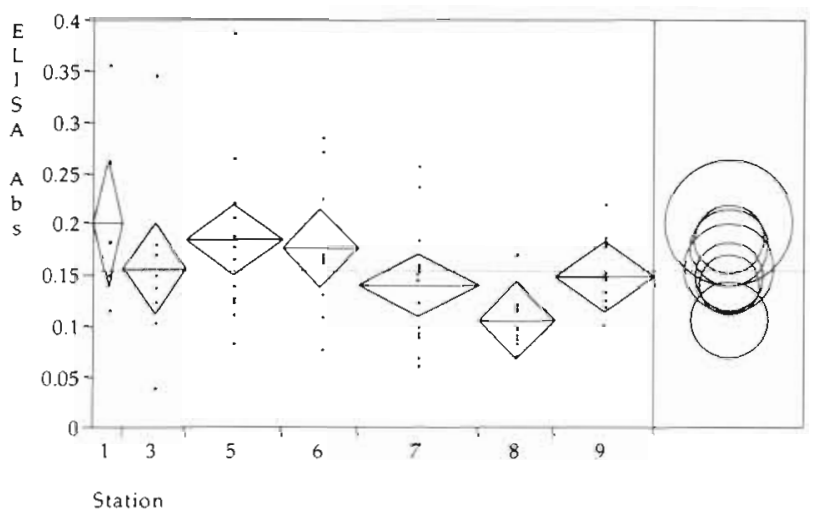

Fig. 2. Limanda limanda. P450 1A1 levels in liver microsomes of male dab caught at different stations in the German Bight. Levels are expressed as P450 1A1-ELISA absorbance values (from the same amounts of sample protein). Dots: individual samples; diamonds: group mean (horizontal line), $95 \%$ confidence interval (height of diamond), and group size (width). Comparison circles (right) have a diameter corresponding to the $95 \%$ confidence interval of each group, allowing visual comparison of group means. Circles for means that are significantly different $(p<0.05)$ either do not intersect or intersect slightly, with an outside angle of intersection of less than $90^{\circ}$ 
In Fig. 1, a Western blot with liver samples of a few selected individuals from different stations in the German Bight gradient is shown, demonstrating the cross-reactivity of the anti-cod P450 1A1 antibody with a single protein band at approximately 58000 daltons in each of the dab samples. The differences in staining intensity reflect different concentrations of the P450 1 A1 protein in total protein in the sample. Immunoquantitation using ELISA is based on a similar principle, where the absorbance reading in the sample well reflects the level of $\mathrm{P} 4501 \mathrm{~A} 1$ protein in the sample, again relative to total protein in the sample.

The P450 1A1 - ELISA absorbance readings from the different sets of liver samples are shown in Figs. 2 to 4 . In male liver microsomes (Fig. 2), significant differences between the stations are observed, with $\operatorname{Stn} 8$ being generally lowest, and significantly lower than Stns $1,5 \& 6(p<0.05)$. The overall effect of station on the ELISA response has a borderline significance of $\mathrm{p}=0.0584$ in ANOVA. In the set of female liver microsomes (Fig. 3) Stns $1 \& 5$ were missing. Again, Stn 8 showed the lowest levels, being significantly lower than Stn 3. Interestingly, a few individuals at Stns $6,7 \& 9$ also had very high ELISA values.

In the set of liver post-mitochondrial supernatants, significant differences were observed in the P450 1A1 - ELISA levels between juvenile and mature fish, with juveniles being higher than mature fish $(p<0.01)$. In the juvenile fish, no sex differences were observed, and also no effects of station (but note that Stns 3 \& 8 were not represented in the juvenile samples). In Fig 4, these juveniles are compared with mature fish of both sexes. In the mature fish, however, male fish had significantly higher levels than females $(p<0.001)$. Since some of the stations contain too few males to analyze separately, and the trend in the data seem to be the same for the 2 sexes, they are presented together here. Separate analysis of the females, however, reveals a significant difference between Stn 3 (highest) and Stns $8 \& 9$ (lowest). The effect of the male samples on the mature set (Fig. 4) is generally to pull the levels of all stations upwards, but especially the levels in Stns 6 \& 9. Correlation analyses of log-transformed data pooled by station showed male liver postmitochondrial supernatants to be well correlated both with male and female liver microsomal samples $(\mathrm{r}=$ $0.78, p=0.07$ and $r=0.85, p=0.07$, respectively), whereas female samples did not correlate well with any of these.

In head kidney microsomes, a slightly different pattern was observed (Fig. 5). Here, Stn 9 was lower than Stn 8, and a decrease of P450 1A.1 levels was observed in the innermost Stns 1 \& 3 . The ANOVA. shows an overall effect of station with $p=0.004$, and Stn 9 is significantly lower than Stns 3, 5 \& 6, whereas

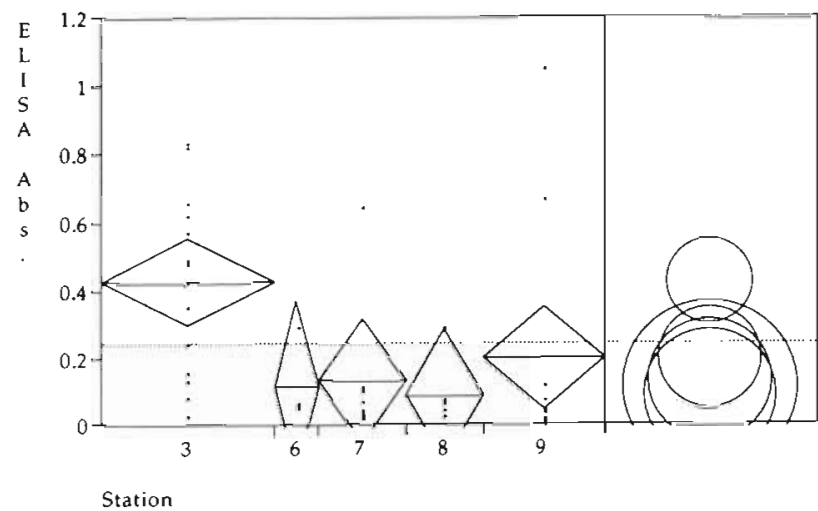

Fig. 3. Limanda limanda. P450 1A1 levels as ELISA absorbance values in liver microsomes of female dab from different stations in the German Bight. For explanation of symbols, see caption to Fig. 2

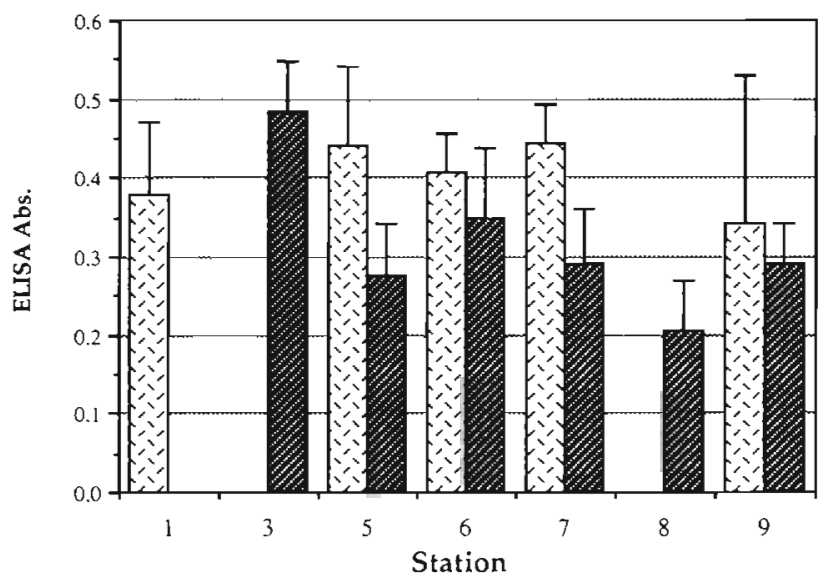

Fig. 4. Limanda limanda. P450 1 A 1 levels as ELISA absorbance values in liver post-mitochondrial supernatants of juvenile (light bars) and mature (dark bars) dab from different stations in the German Bight. Means and standard errors are shown

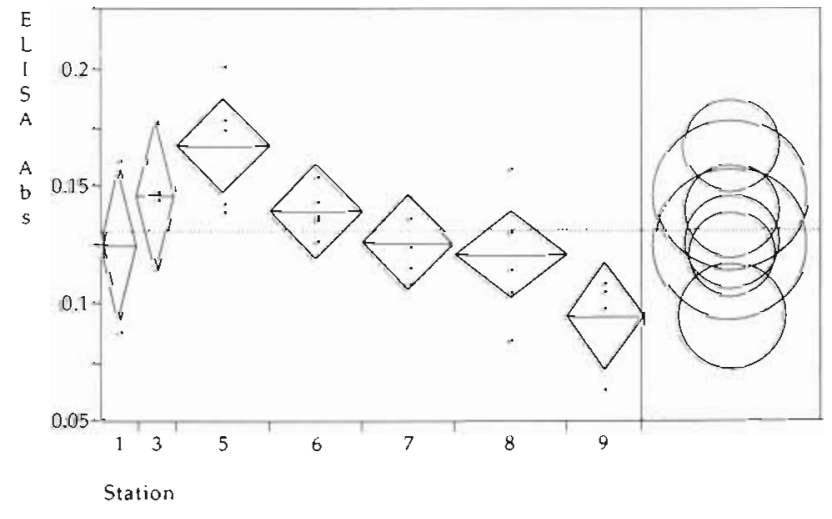

Fig. 5. Limanda limanda. P450 $1 \mathrm{~A} 1$ levels as ELISA absorbance values in head kidney microsomes of male dab from different stations in the German Bight. For explanation of symbols, see caption to Fig. 2 
Stn 8 is significantly lower than Stn 5 only ( $p<0.05$ ). The ELISA pattern in trunk kidney post-mitochondrial supernatants followed the head kidney values closely (Fig. 6). Although only Stn 9 is significantly different from the other stations, being lower than all of these, the correlation between log-transformed data from head and trunk kidney pooled by station was very strong $(\mathrm{s}=0.92, \mathrm{p}=0.009)$. In trunk kidney, EROD activities were also measured (Fig. 7). Again, Stn 9 was lowest, and $\operatorname{Stn} 3$ the highest. However, Stns 5 \& 6 were much lower in this case, being almost as low as Stn 9 . A correlation analysis of these data in individual trunk kidney samples indicates these differences, with an $r$ value of 0.38 ( $p=0.059)$.

The observed responses in the P450 1A1 levels in liver and kidney all show the same trend, with elevated levels in the innermost stations of the gradient, especially Stn 3. At Stn 9, somewhat different results were obtained in liver and kidney. The reason

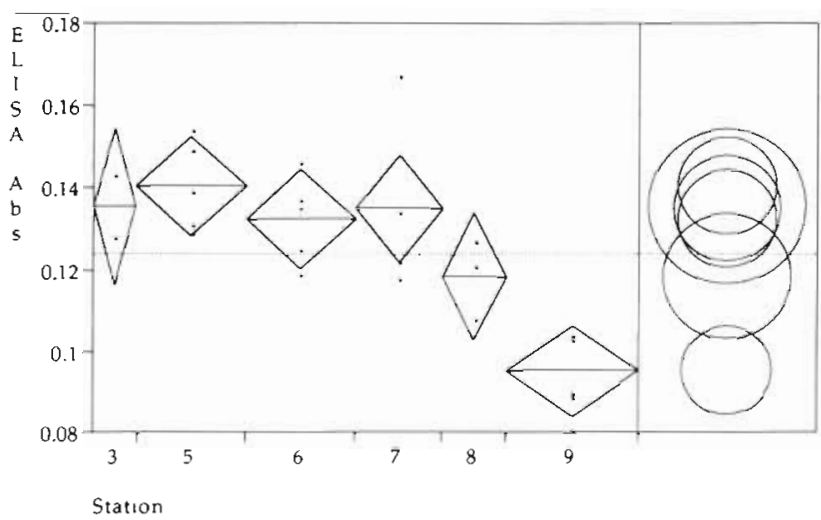

Fig. 6. Limanda limanda. P450 $1 \mathrm{~A} 1$ levels as ELISA absorbance values in trunk kidney post-mitochondrial supernatants of male dab from different stations in the German Bight. For explanation of symbols, see caption to Fig. 2. Individual values represent in this case pools of tissue from 3 to 4 fish

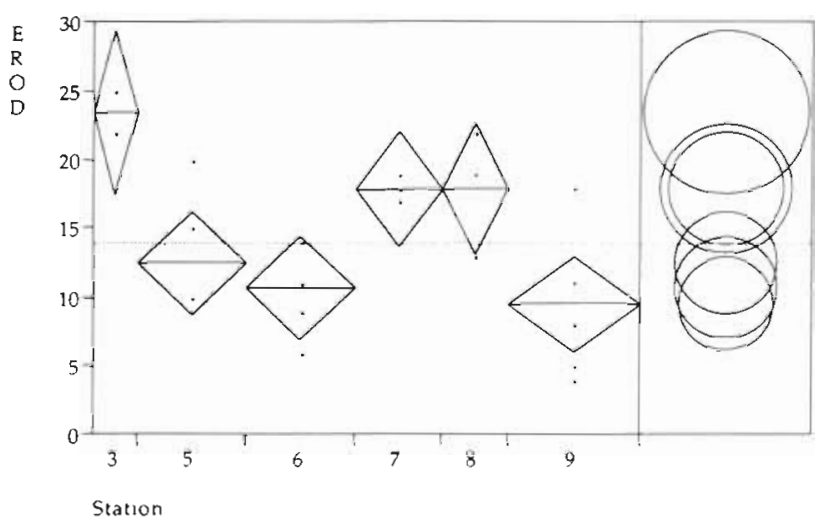

Fig. 7. 7-Ethoxyresorufin O-deethylase (EROD) activity in trunk kidney post-mitochondrial supernatants of male dab from different stations in the German Bight. Samples are the same as in Fig. 6 for this is unknown, but may be attributed to different temporal responses of the 2 organs to contamination. Migration into or from a contaminated area may thus be differently reflected in the 2 organs.

Higher levels were generally observed in males compared to females. This is in accord with other studies on the effects of reproduction on the P450-system of fish (e.g. Forlin \& Haux 1990, Larsen et al. 1992). The lack of a complete station set of juvenile samples makes it difficult to speculate whether these would have reflected the contamination situation better, but the P450 1A1 levels were generally higher in juveniles in all stations where parallel sets were available.

Since only a limited set of results from chemical analyses were available, and these were performed on separately sampled female dab (Cofino et al. 1992), a thorough, multivariate analysis has not been performed. We have, however, performed correlation analyses between Iog-transformed chemistry data (PCBs and organochlorine pesticides), pooled by station, and log-transformed P450 1A1 data, pooled by station. From these studies, we found no correlation between liver P450 data and PCBs (not shown). However, $o, p^{\prime}$-DDD correlated well with P450 1A.1 in male liver microsomes $(\mathrm{r}=0.90, \mathrm{p}<0.02)$, whereas $\beta-\mathrm{HCH}$ and $o, p^{\prime}$-DDE showed significant negative correlation $(\mathrm{p}<0.025)$ with P450 1A1 levels in male liver microsomes and mature male post-mitochondrial fractions, respectively. Interestingly, $p, p^{\prime}$-DDT correlated well with P450 1A1 in these samples as well, although this may not be significant ( $p=0.07$ to 0.09 ). In kidney, the best correlation with PCB data was between \#138 and head kidney P450 1A1, with $r=0.74$ at $p<0.10$. Again, good correlations were observed with organochlorines, however this time only with $\beta-\mathrm{HCH}$ and lindane giving significant results $(p<0.02)$. Poor correlations were observed in all the other parameters (not shown).

Although strong correlations between a chemical and a biological response make it tempting to speculate on inducing properties and effects, great caution is required when discussing the significance of these results. First of all, these correlations have been performed on station means, and not on individual results, since such data were not available from the same fish. Furthermore, many of the organochlorine pesticides, e.g. the DDT group, have been shown in laboratory studies not to induce the P450 system in fish, as opposed to the effects in mammals (Addison et al. 1977). In this field study a vast number of chemicals have not been analyzed, many of which will have potential inducing effects on the cytochrome P450 system. A strong correlation may therefore indicate only that other chemicals with similar physico-chemical properties are present and co-vary with the measured substances. The different correlation profiles ob- 
served in different tissues (in gill tissue, a strong correlation was observed between $\mathrm{P} 4501 \mathrm{~A} 1$ levels and PCB \#52: Stagg et al. 1992) indicate not only that various contaminants reach organs and tissues at different rates, but also that there may be organ-specific responses to the different chemicals. These observations are also interesting and deserve further study.

In the liver microsomal samples from the oil platform stations, low P450 1A1 levels and no differences between stations were observed, indicating no effects of inducing agents on these fish (results not shown) The mean of the levels found with the ELISA technique was lower than the mean for the German Bight gradient (A492 $=0.13$ and 0.15 , respectively). The absence of induction indicates that the hydrocarbon contaminants present in the sediments are not bioavailable to the dab in this area, or the dab caught were just passing by during a migration.

Several factors may complicate the interpretation of results in such a field study, e.g. sexual maturation, migration, dietary factors, temperature, and synergistic and antagonistic effects of various contaminants. Although we tried to minimise many of these during sampling, their effects cannot be ruled out. The present results show a contamination gradient in the German Bight, with effects on cytochrome P450 1A1 levels in liver and kidney. Immunodetection of this response is a convenient way to monitor for such effects, since a large number of samples can be screened simultaneously. Also, sampling, storage and handling is not critical since antibodies will detect denatured as well as native protein. The present study provided useful experience with the technique in large-scale field monitoring programmes. We have since practised the ELISA technique on board research vessels during cruises, and will continue to work with developing monoclonal antibodies as a basis for simple and standardized assay protocols.

Acknowledgements. This study was supported by grants from the Royal Norwegian Council for Scientific and Industrial Research (NTNF), the Norwegian Fisheries Research Council (NFFR), and the National Swedish Environmental Protection Board. We thank Kjersti A. Helgesen for excellent technical assistance, and we gratefully acknowledge the efforts of the organizers (Drs A. R. D. Stebbing and V. Dethlefsen), and of our colleagues during the workshop (Drs Addison, Renton, Eggens, Stagg, Hogstrand, Hansen \& Pluta) for sharing data and samples, and for interesting discussions on the results.

\section{LITERATURE CITED}

Addison, R. F., Zinck, M. E., Willis, D. E. (1977). Mixed function oxidase systems in trout (Salvelinus fontinalis) liver: absence of induction following feeding of $p, p=D D T$ or $p, p^{\prime}$-DDE. Comp. Biochem. Physiol. 75C: 39-43
Boon, J. P., Everaarts, J. M., Hillebrand, M. T. J., Eggens, M. L., Peijnenburg, J., B., Goksøyr, A. (1992). Changes in levels of hepatic biotransformation enzymes and haemoglobin in female plaice (Pleuronectes platessa) after oral administration of a technical PCB mixture (Clophen A40). Sci. tot. Environ. 114: 113-133

Bradford, M. M. (1976). A rapid and sensitive method for the quantitation of microgram quantities of protein utilizing the principle of protein-dye-binding. Analyt. Biochem. 72: $248-254$

Cofino, W. P., Smedes, F., de Jong, S. A., Abarnou, A., Boon, J. P., Oostingh, I., Davies, I., M., Klungsøyr, J., Law, R. J., Whinnett, J. A., Schmidt, D., Wilson, S. (1992). The chemistry programme. Mar. Ecol. Prog. Ser 91: 47-56

Daan, R., van het Groenewoud, H., de Jong, S. A., Mulder, M. (1992). Physico-chemical and biological features of a drilling site in the North Sea, 1 year after discharges of oilcontaminated drill cuttings. Mar. Ecol. Prog. Ser. 91 $37-45$

Eggens, M., Galgani, F., Klungsøyr, J., Everts, J. (1992) Hepatic EROD activity in dab Limanda limanda in the German Bight using an improved plate-reader method Mar, Ecol. Prog. Ser. 91: 71-75

Förlin, L., Haux, C. (1990). Sex differences in hepatic cytochrome P-450 monooxygenase activities in rainbow trout during an annual reproductive cycle. J. Endocrinol. 124: $207-213$

Goksøyr, A. (1985). Purification of hepatic microsomal cytochromes P-450 from ß-naphthoflavone-treated Atlantic cod (Gadus morhua), a marine teleost fish. Biochim. Biophys. Acta 840: 409-417

Goksøyr, A. (1991). A semi-quantitative cytochrome P450IA1 ELISA: a simple method for studying the monooxygenase induction response in environmental monitoring and ecotoxicological testing of fish. Sci. tot. Environ. 101: 255-262

Goksøyr, A., Andersson, T., Buhler, D. R., Stegeman, J. J., Williams, D. E., Förlin, L. (1991c). Immunochemical crossreactivity of $\beta$-naphthoflavone-inducible cytochrome P-450 (P4501A) in liver microsomes from different fish species and rat. Fish Physiol. Biochem. 9: 1-13

Goksøyr, A., Förlin, L. (1992). The cytochrome P450 system in fish, aquatic toxicology, and environmental monitoring. Aquat. Toxicol. 22: 287-312

Goksøyr, A., Larsen, H. E., Husøy, A.-M. (1991b). Application of a cytochrome P450 IA1-ELISA in environmental monitoring and toxicological testing of fish. Comp. Biochem. Physiol. 100C: $157-160$

Goksøyr, A., Solberg, T S., Serigstad, B. (1991a). Immunochemical detection of cytochrome P450lA1 induction in cod (Gadus morhua) larvae and juveniles exposed to a water soluble fraction of North Sea crude oil. Mar. Pollut. Bull. 22: 122-127

Larsen, H. E., Celander, M., Goksøyr, A. (1992). The cytochrome P450 system of Atlantic salmon (Salmo salar); II. Variations in hepatic catalytic activities and isozyme patterns during an annual reproductive cycle. Fish Physiol. Biochem. 10: (in press)

Payne, J. F., Bauld, C., Dey, A. C., Kiceniuk, J. W., Williams, U. (1984). Selectivity of mixed-function oxygenase induction in flounder (Pseudopleuronectes americanus) collected at the site of the Baie Verte, Newfoundland oil spill. Comp. Biochem. Physiol. 79C: 15-19

Payne, J. F., Fancey, L. L., Rahimtula, A. D., Porter, E. L. (1987). Review and perspective on the use of mixed-function oxygenase enzymes in biological monitoring. Comp. Biochem. Physiol. 86C: 233-245

Pesonen, M., Anderson, T. (1987). Subcellar localization and 
properties of cytochrome P-450 and UDP glucuronosyltransferase in the rainbow trout kidney. Biochem. Pharmacol 36: 823-829

Pesonen, M., Celander, M., Förlin, L., Andersson, T (1987). Comparison of xenobiotic biotransformation enzymes in kidney and liver of rainbow trout (Salmo gairdnen). Toxicol appl. Pharmacol. 91: 75-84

Renton, K. W., Addison, R. F. (1992). Hepatic microsomal mono-oxygenase activity and P450IA mRNA in North Sea dab Limanda limanda from contaminated sites. Mar. Ecol. Prog. Ser. 91: 65-69
Rijnsdorp, A. D., Vethaak, A. D., van Leeuwen, P. I. (1992). Population biology of dab Limanda limanda in the southeastern North Sea. Mar. Ecol Prog. Ser. 91: 19-35

Stagg, R., Goksoyr, A., Rodger, G. (1992). Changes in branchial $\mathrm{Na}^{+}, \mathrm{K}^{+}$-ATPase, metallothionein and P450 $1 \mathrm{~A} 1$ in dab Limanda limanda in the German Bight: indicators of sediment contamination? Mar. Ecol. Prog. Ser. 91: 105-115

Stebbing, A. R. D., Dethlefsen, V. (1992). Introduction to the Bremerhaven Workshop on Biological Effects of Contaminants. Mar. Ecol. Prog. Ser. 91.1-8 